\title{
Coordinated Control of Interconnected Microgrid and Energy Storage System
}

\author{
Md. Asaduz-Zaman', Md. Habibur Rahaman², Md. Selim Reza ${ }^{3}$, Md. Mafizul Islam ${ }^{4}$ \\ ${ }^{1}$ Department of TMDM, Bangladesh University of Textiles, Bangladesh \\ ${ }^{2}$ Department of Electrical and Computer Engineering, Rajshahi University of Engineering \& Technology, Bangladesh \\ ${ }^{3}$ Department of EEE, Bangladesh Army University of Engineering \& Technology, Bangladesh \\ ${ }^{4}$ Department of TMDM, Bangladesh University of Textiles, Bangladesh
}

\section{Article Info \\ Article history: \\ Received Dec 29, 2017 \\ Revised Jul 28, 2018 \\ Accepted Aug 15, 2018 \\ Keyword: \\ A state of charge \\ Energy storage system \\ Interconnected microgrid \\ Load frequency control \\ Spinning reserve}

\begin{abstract}
Several microgrids can be interconnected together to enhance the grid reliability and reduce the cost of supplying power to an island area where conventional power grid cannot be connected. Source and load demand do not properly balance always. Besides that, sometimes power and frequency fluctuation has occurred in MG at island mode. Need to design a special control for maintaining the state of charge (SoC) of energy storage system. This paper proposes a new power supply system for an island area that interconnects two microgrids with a single energy storage system (ESS). An algorithm has been proposed that control the microgrids energy storage system for spinning reserve and load power/frequency regulation purpose. The minimum loading constraints of diesel engine generator (DEG) is considered and the SOC of the ESS is properly maintained.
\end{abstract}

Copyright $(0) 2018$ Institute of Advanced Engineering and Science. All rights reserved.

\section{Corresponding Author:}

Md. Habibur Rahaman,

Department of Electrical and Computer Engineering,

Rajshahi University of Engineering \& Technology,

Bangladesh.

Email: habibieee@yahoo.com

\section{INTRODUCTION}

The micro grid is considered as the smart electrical power management system for the isolated areas that cannot access to the conventional power grid. The operation and control strategies may be different according to connection configurations of the micro grid.

An MG can only supply a maximum load capacity of 10 MVA [1]. However, several microgrids can be interconnected to form larger power pool to meet greater power demands. It also has more redundancy and ensures better supply reliability [1]. Interconnected microgrids are generally called multi-microgrid (MMG); it is a relatively new concept. Interconnected microgrids can achieve greater stability and controllability with a distributed control structure. The possibility of having a large number of controllable MGs, DG units and MV loads under demand side management (DSM) control requires the use of a hierarchical control scheme that enables an efficient control and management of this kind of system [2].

Since energy storage system (ESS) is an integral part of MGs and it can provide fast active power compensation, it also can be used to improve the performance of load frequency controller (LFC) [3]-[4]. The minimum loading constraints of diesel engine generator are considered and the state of charge (SOC) of the ESS is properly maintained. Objectives also include optimum utilization of total wind, solar PV energy, and ESS contribution to the interconnected microgrid. 


\section{VOLTAGE AND FREQUENCY CONTROL OF MG}

The main purpose of MG is to reduce loss, emissions and cost of energy. Balancing between source and load is a great challenge in isolated MG system. These can be overcomed by using decentralized, centralized, hierarchical or distributed control [5]. It is also great challenge to reduce commutation link failure, to reduce line frequency and voltage fluctuation, to control the primary and central controllers of MGs fighting to each other and the coordination of energy storages (i.e. batteries) etc [6]. In the grid connected mode, similar to a conventional utility system, each DG unit can be controlled to produce real and reactive power (PQ-bus) or generate real power and maintain its terminal voltage (PV-bus) as like as conventional interconnected grid system. The frequency and real/reactive power in a power grid should be under controlled and maintain a smooth balance between power generation and loads.

The control makes an interface between power management and voltage source control (VSC) as shown in Figure 1 [7] in which signal processing block and phase locked loop (PLL) has been used a necessary part of this system.

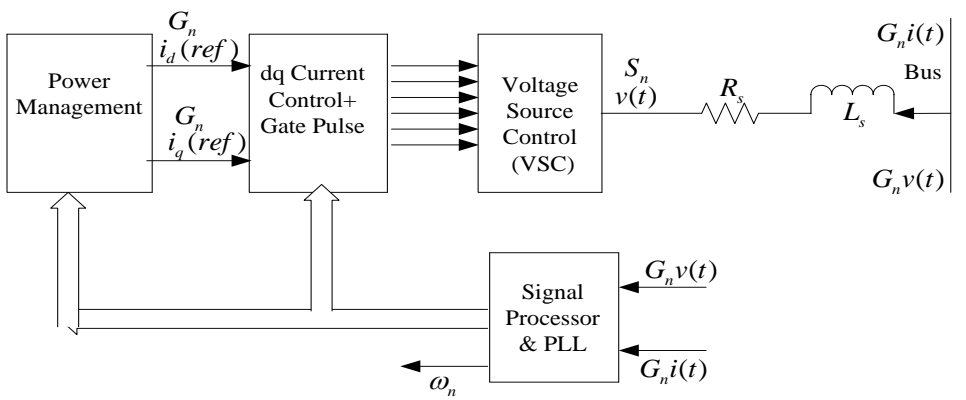

Figure 1. Control procedure of $n^{\text {th }}$ EI-DG unit

\section{THE ENERGY STORAGE CONTROL IN ISLAND MODE}

For mitigating power fluctuation EES is used in MG. Sometimes overcharge and over discharge in EESs may occur due to use of finite number of battery banks. Thus, to maintain a SoC in EES, a suitable control system is necessary. Traditionally autonomous SoC control has been used but now different types of advance controller are used to maintain SoC as shown in Figure 2 [8], this will reduce frequency and power fluctuations of a microgrid.

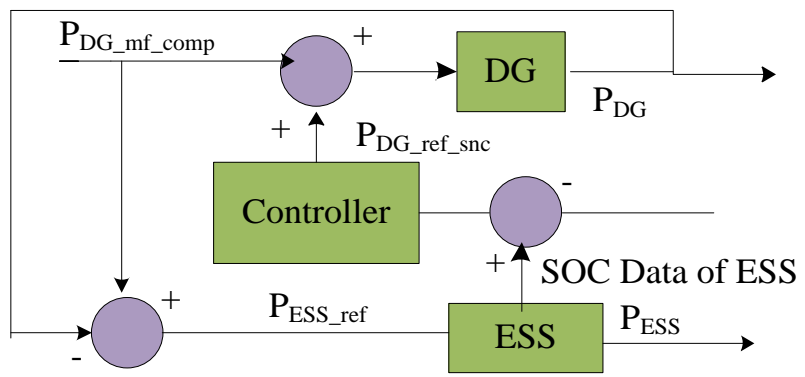

Figure 2. EESs SoC control procedure

The MG has some traditional control procedure but in present day's two types of control system has been used like microgrid management system (MMS) and local controller (LC). An LC system is a local controller that is worked at each MG source and controls the output power of MG based on the parameters sated by MMS. On the other hand, the MMS is a robust and suitable controller which deals with management functions such as fault disconnection and re-synchronization of the microgrid and the load shedding process. 


\section{OPTIMUM SIZING OF EES}

Microgrids is a low voltage distribution network in which design an EES is very important to properly maintain the electricity demand and support in the isolated MGs like in island area [9]-[10]. Very traditional methods are that to store extra energy from renewable sources at low demand and delivering the stored energy during peak demand [11]. The equations given below represent the charging \& discharging equation [12]:

$$
C(t+1)=C(t)-\Delta t P_{t}^{E}
$$

subject to:

$$
\begin{aligned}
& \text { Output power limits: }\left|P_{t}^{E}\right| \leq P_{E}^{\max } \\
& \text { Stored energy limits: } C_{\min } \leq C(t) \leq C_{\max }
\end{aligned}
$$

where, starting limits: $C(0)=C_{S}$

where, $P_{t}^{E}$ is the power supplied by battery banks; $P_{E}^{\max }$ is the maximum charge and discharge rate; $C_{S}$ is the initial stored energy. For safety operation of ESSs, battery management system can be applied. In this system, batteries voltage, current and temperature is controlled from centrally. It's a great challenge to design EES avoiding optimizing problems [13]. The lifetime of battery depends on power and energy densities, operating conditions and cycle life etc. Considering those factors Lithium-ion, Sodium Sulphur and Zinc bromine batteries or Nickel-cadmium batteries have good characteristics [14].

\section{CONFIGURATION OF THE PROPOSED SYSTEM}

The studied interconnected MG and ESS is shown in Figure 3 One micro grid consists of a DEG, solar PV and wind power, and load. The other micro grid has DEG, wind power and load. The tie-line connected MMG system has a common ESS.

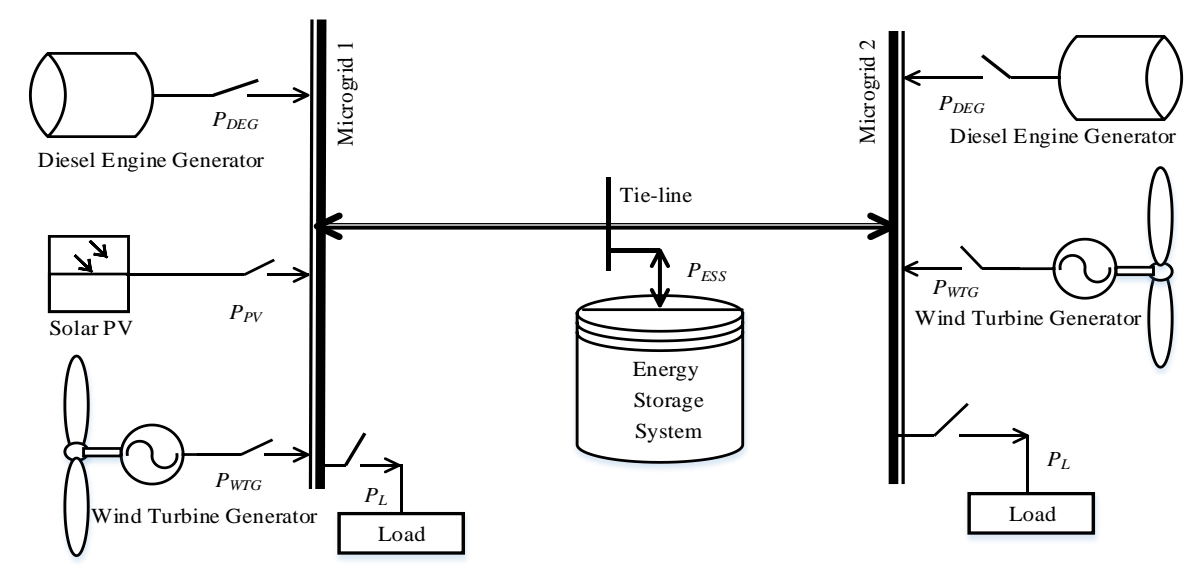

Figure 3. Schematic diagram of interconnected microgrid and ESS

Combining the aforementioned various renewable energy resources with energy storage systems and diesel engine generator in an interconnected system, the generated electric energy can be effectively distributed and controlled to meet the energy requirement of the connected loads.

\section{POWER SYSTEM MODELLING} section.

The modeling of the different components of the proposed microgrid system is presented in this 


\subsection{Diesel Engine Generator (DEG)}

To meet the required load demand, any standby DEG works continuously to supply the power that is normally connected to the microgrid system. The transfer functions of the DEG can be written as follows considering a first order lag [15],

$$
G_{D E G}(s)=\frac{\Delta P_{D E G}}{\Delta f}=\frac{K_{D E G}}{1+s T_{D E G}}
$$

where, $K_{D E G}$ and $T_{D E G}$ are the gain and time constants respectively.

The DEG should be operated economically to control the governing system so that the generation costs will be lower. The diesel generators optimum generated output power is $70-89 \%$ from the rated power [16]. The capacity of a DEG is normally sated almost $30-50 \%$ or more [17]-[18]. Therefore, the relation can be written as,

$$
P_{D E G} \geq P_{D E G(\text { Min })}
$$

where, $P_{D E G}$ and $P_{D E G(\operatorname{Min})}$ is the operating power and lower limit constraints of the DEG, respectively.

\subsection{Wind Turbine Generator (WTG)}

The generated output power from a WTG is greatly depended on wind speed $\left(V_{W}\right)$. Thus, the wind turbine mechanical power output can be written as follows [19]:

$$
P_{W T}=\frac{1}{2} \rho A_{r} C_{P} V_{W}^{3}
$$

where, $\rho$ represents the air density in $\mathrm{kg} / \mathrm{m}^{3}, A_{r}$ represents the swept area of the blade in $\mathrm{m}^{2}$, and $C_{p}$ represents the power coefficient. The transfer function can be written as follows,

$$
G_{W T G}(s)=\frac{\Delta P_{W T G}}{\Delta P_{W T}}=\frac{K_{W T G}}{1+s T_{W T G}}
$$

where, $K_{W T G}$ and $T_{W T G}$ represents the gain and time constants of WTG respectively.

\subsection{Solar Photovoltaic (PV)}

A solar PV system consists of many small cells connected to provide the desired voltage and current. The output power of the PV system can be expressed as [15],

$$
P_{P V}=\eta S \phi\left[1-0.005\left(T_{a}+25\right)\right]
$$

where, $\eta$ is conversion efficiency of the PV array, $S$ is measured the area of PV array $\left(m^{2}\right), \varphi$ is solar irradiation $\left(\mathrm{kW} / \mathrm{m}^{2}\right)$ and $T_{a}$ is ambient temperature $\left({ }^{\circ} \mathrm{C}\right)$. The transfer function of PV can be given by a simple linear first order lag,

$$
G_{P V}(s)=\frac{\Delta P_{P V}}{\Delta \phi}=\frac{K_{P V}}{1+s T_{P V}}
$$

where, $K_{P V}$ and $T_{P V}$ represents the gain constant and time constant of solar PV respectively.

\subsection{Energy Storage System}

Energy storage systems are important devices to supply energy of the hybrid power system very fast to maintain system stability [15]. The transfer functions of the energy storage systems can be taken as first order lag,

$$
G_{E S S}(s)=\frac{\Delta P_{E S S}}{\Delta f}=\frac{K_{E S S}}{1+s T_{E S S}}
$$


where, $K_{E S S}$ is gain constant and $T_{E S S}$ is the time constant of ESS.

Hence, a relatively simple model is used in this work to represent charge/discharge process and the SoC of ESS [20].

$$
\Delta S O C=-\frac{\Delta P_{E S S}}{W_{b} \times 3600 s}
$$

where, $W_{b}$ is the battery capacity. The selection of optimum sizes of EES has been described in section 4 .

\subsection{Power Deviation and System Frequency Variation}

The output power should be controlled based on power demand to maintain stable operation [15]. The total power generation $\left(P_{T}\right)$ is the algebraic summation of all generators like diesel engine generator $\left(P_{D E G}\right)$, wind power $\left(P_{W T G}\right)$, solar photovoltaic power $\left(P_{P V}\right)$ and power of energy storage system $\left(P_{E S S}\right)$ as shown in Figure 3.

$$
P_{T}=P_{D E G}+P_{W T G}+P_{P V} \pm P_{E S S}
$$

The difference between $P_{T}$ and $P_{D}$ is given by Eq. 13 where $P_{D}$ represents the demanded power [20].

$$
\Delta P_{e}=P_{T}-P_{D}
$$

because system frequency is changed with net power variation, the system frequency variation $\Delta f$ is calculated by,

$$
\Delta f=\frac{\Delta P_{e}}{K_{s y s}}
$$

where, $K_{\text {sys }}$ represents the system frequency. Since an inherent time delay exists between system frequency variation and power deviation, the transfer function for system frequency variation to per unit power deviation can be expressed by,

$$
G_{s y s}(s)=\frac{\Delta f}{\Delta P_{e}}=\frac{1}{K_{s y s}\left(1+s T_{s y s}\right)}=\frac{1}{D+M s}
$$

where, $M$ and $D$ are the equivalent inertia constant and damping constant of the microgrid system respectively [19].

\section{INTERCONNECTION OF MICROGRIDS WITH TIE-LINE}

Reliable power supply to the connected load may be achieved by the interconnection of neighboring isolated MGs through tie-line. Tie-line is used to exchange energy between control areas to provide inter-area support in case of faulted condition. If there is an unbalance situation occurs between generation and load, the deviation in frequency for a particular area occurs [19]. Interconnected microgrid with two-area interconnection is represented as shown in Figure 4.

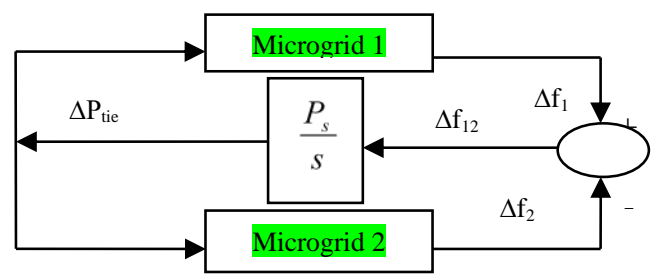

Figure 4. Modelling of tie-line connection 
Expressing the tie-line power deviation $\left(\Delta P_{\text {tie }}\right)$ in terms of frequency deviation $(\Delta f)$ and synchronizing power coefficient $\left(P_{s}\right)$ is represented as,

$$
\Delta P_{\text {tie }}=P_{s}\left(\int \Delta f_{1} d t-\int \Delta f_{2} d t\right)
$$

taking the Laplace transform we have,

$$
G_{\text {tie }}=\frac{\Delta P_{\text {tie }}(s)}{\Delta f(s)}=\frac{P_{s}}{s}
$$

\section{OPERATION STRATEGY}

In MGs system, change in frequency depends upon changes in load demand; whenever load demand increases system frequency decreases and vice-versa. When the change in frequency $(\Delta f)$ becomes negative, the ESS supplies power to the system. If SOC of the battery is greater than $S O C_{L}$, then ESS supply power to the system and get discharged. Otherwise, ESS does not deliver power. When the change in frequency becomes positive, the ESS is charged. Before charging the ESS its SOC is compared to its upper limit of the state of charge $\left(S O C_{U}\right)$. If SOC is less than its $S O C_{U}$ then ESS is in charging mode and consuming power from the system, otherwise, ESS does not charge. The control strategy of ESS is shown in Figure 5.

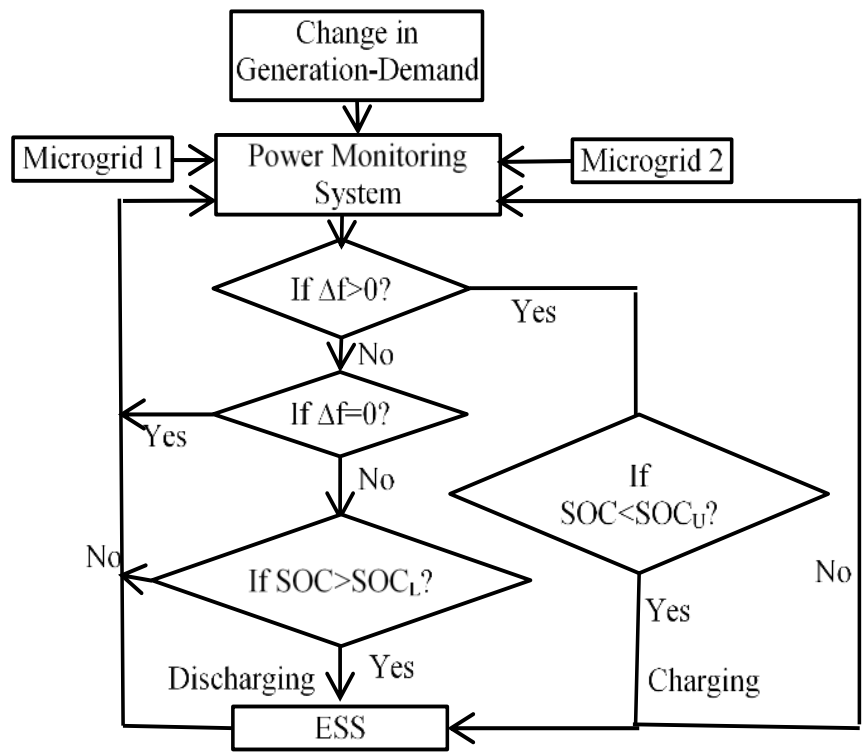

Figure 5. Proposed algorithms for ESS control

The total renewable power generation $\left(P_{R}\right)$ by the microgrid system is the algebraic summation of wind power $\left(P_{W T G}\right)$, solar photovoltaic power $\left(P_{P V}\right)$.

$$
P_{R}=P_{W T G}+P_{P V}
$$

the difference between total renewable power generation $P_{R}$ and power demand reference $P_{D}$ is the extra power and given by equation 16 .

$$
\Delta P_{E}=P_{R}-P_{D}
$$

If $\Delta P_{E}>0$, the remaining power will be used to charge the ESS. If the batteries are completely charged, the excess power is dumped. If $\Delta P_{E}<0$, the remaining power will be given by the ESS or by the diesel generator, depending on the economic dispatch strategy. If the ESS is able to give $\Delta P_{E}$, then ESS discharge and diesel generator turn off. But if the ESS is not able to give $\Delta P_{E}$, the diesel generator turns on, 
and the ESS will neither be charged nor discharged. In this case, only ESS will be used for frequency regulation purpose.

\section{SIMULATION RESULTS AND ANALYSIS}

Results and analysis of the time domain simulation of the system are presented in this section. For the purpose of calculation, all input and output quantities in the plots are considered in per unit (p.u.) values. Parameter values of the configurations are taken from [15], [19], [21]-[26] and listed in Table 1.

Table 1. Parameter Values of the Studied MG Systems

\begin{tabular}{llcc}
\hline \multicolumn{1}{c}{ Parameter } & \multicolumn{1}{c}{ Definition } & MG1 & MG2 \\
\hline$M(p u)$ & Inertia constant & 0.8 & 0.7 \\
$D(p u)$ & Damping constant & 0.02 & 0.03 \\
$T_{D E G}(s)$ & DEG time constant & 2 & 2 \\
$T_{W T G}(s)$ & WTG time constant & 1.5 & 1.5 \\
$T_{P V}(s)$ & PV time constant & 1.8 & - \\
$P_{S}(p u)$ & Syn. power coefficient & \multicolumn{2}{c}{0.0754} \\
$S O C_{U}$ & Upper limit of SOC & \multicolumn{2}{c}{0.7} \\
$S O C_{L}$ & Lower limit of SOC & \multicolumn{2}{c}{0.3} \\
$S O C_{0}$ & Initial state of SOC & \multicolumn{2}{c}{0.4} \\
$T_{E S S}(s)$ & ESS time constant & \multicolumn{2}{c}{0.1} \\
\hline
\end{tabular}

Simulation time for the system is taken to be 300s. The SOC of ESS is properly controlled. Figure 6(a) to (c) show the generated power and load profiles in each MGs and their total variation.
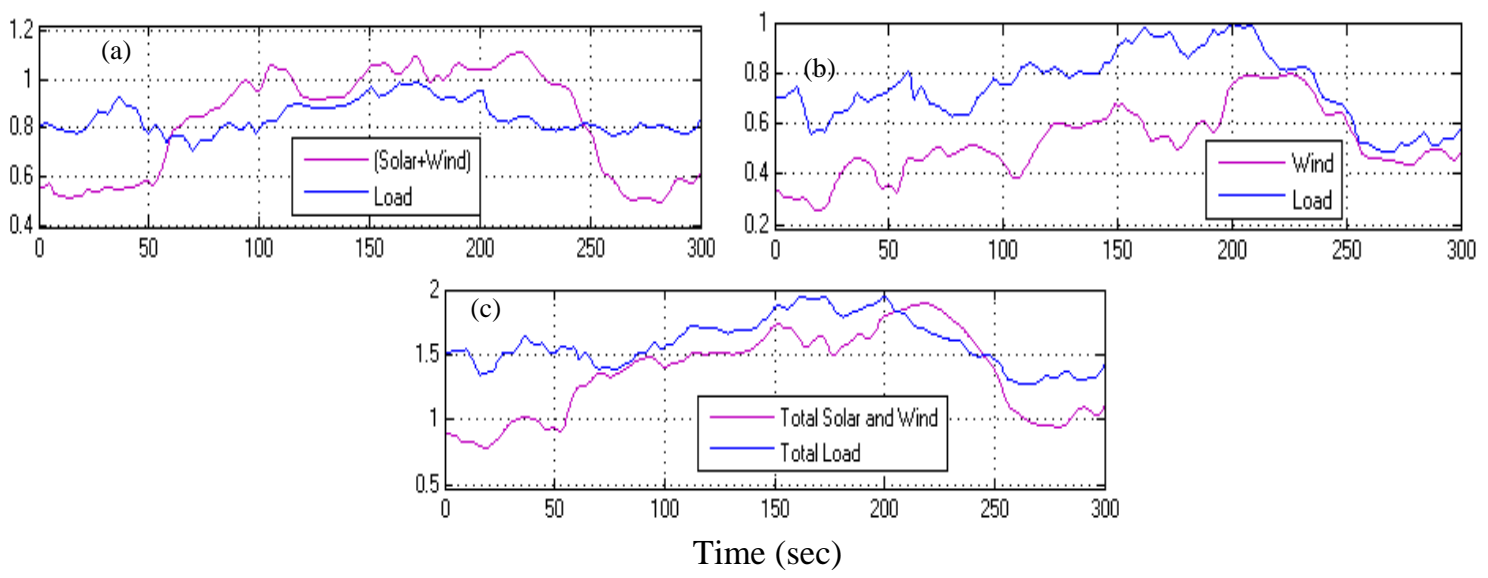

Figure 6. Power and load profiles at (a) MG1; (b) MG2; (c) Total (MG1+MG2)

Figure 7 shows the power output of DEGs and Figure 8 shows the frequency deviation at MG1 and MG2, respectively. Figures 9 (a) to (c) show the deviations of ESS Power, ESS SOC, and Tie-line power.
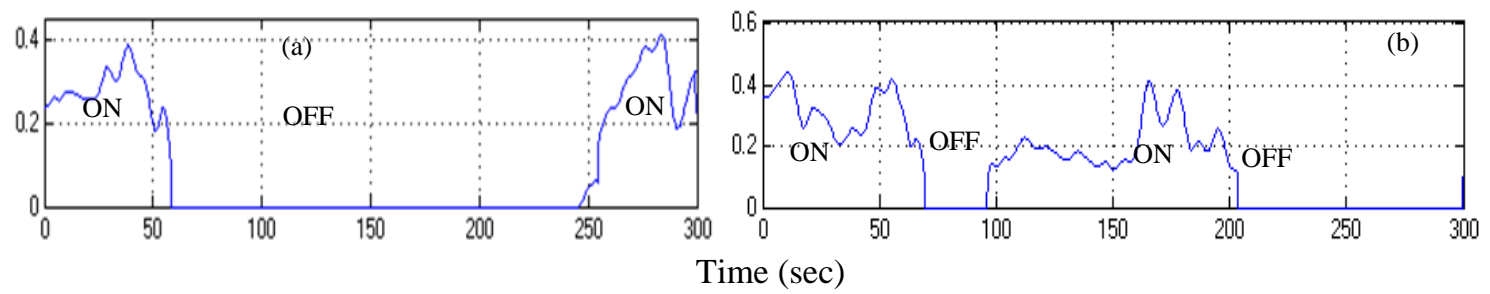

Figure 7. DEG power output at (a) MG1; and (b) MG2 

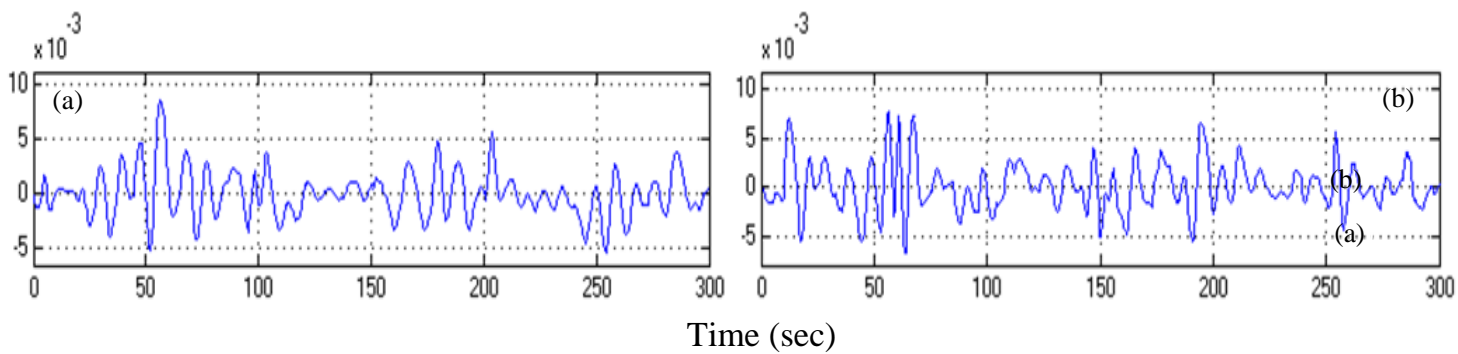

Figure 8. Deviation of (a) Frequency at MG1, and (b) Frequency at MG2
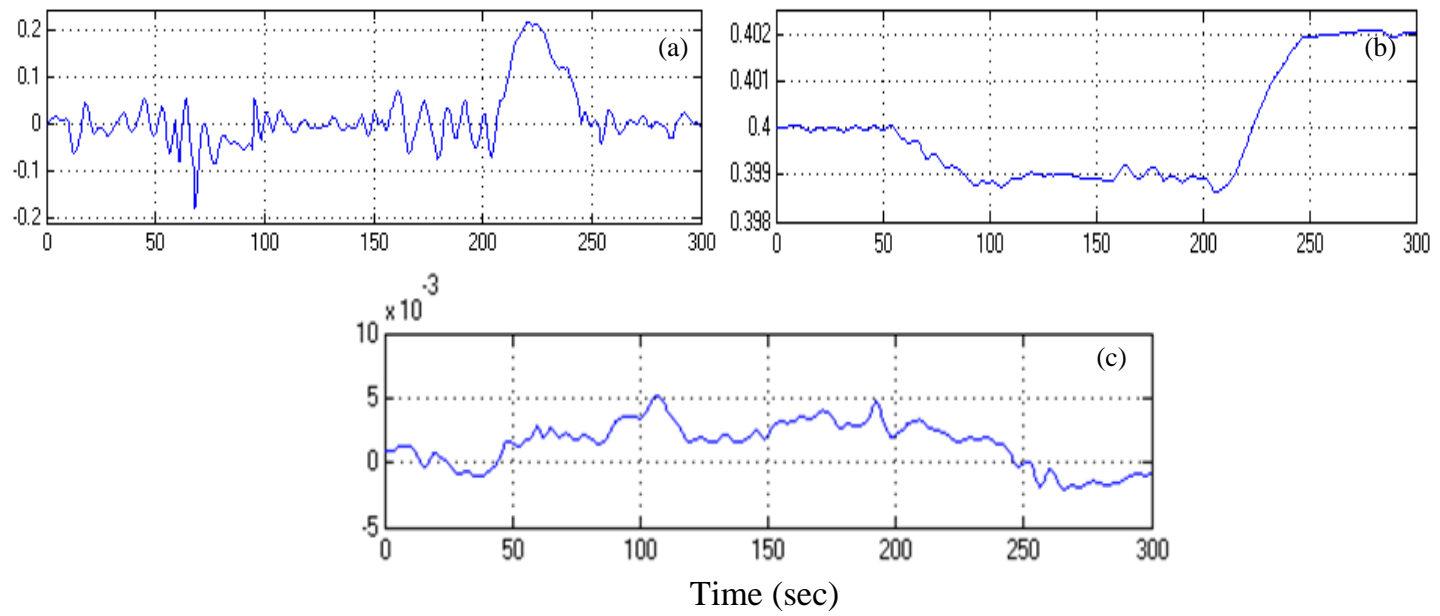

Figure 9. Deviation of (a) ESS Power; (b) ESS SOC; (c) Tie-line power

From 0 to $58 \mathrm{~s}$ both the microgrids operate independently. The renewable energy at each MG is lower than the load. Each DEG supplies the deficit power in the respective MG. There is no energy exchange between MG1 and MG2. The ESS is used only for load frequency control of the microgrid. From 58 to 245s surplus renewable energy is available at MG1 and extra energy is transferred from MG1 to MG2 depending on the load demand or stored at the ESS. In this case DEG1 at MG1 is stopped. From 67 to the 96s output power of DEG2 is lower than the minimum loading constraints i.e. less than $0.1 \mathrm{pu}$. To operate economically, DEG2 is stopped and ESS is used as the spinning reserve. After 96s DEG2 starts and continues up to about 203s. After 203s sufficient renewable energy is available compared to load. The extra energy is stored at ESS. In this case, both DEG is stopped.

At about 245s the MG2 has lower renewable energy and DEG2 should be started. But by considering minimum loading constraints, the DEG2 is stopped. Only DEG1 is started and deficit energy at MG2 is transferred from MG1. Figure 9 (a) and 9 (b) show that when ESS is used as the spinning reserve, the SOC is decreased. Also, SOC increases if sufficient renewable energy is available and stored at ESS.

\section{CONCLUSION}

Coordinated operations strategy of two interconnected microgrids with a single energy storage system has been proposed in this paper. The required power for the connected loads can be effectively delivered and supplied for the proposed system with appropriate control and effective coordination among various components. The employed mathematical models for the various component of the system are represented by first-order transfer functions to simplify the tasks of system simulation. Simulation results show that a single ESS can be used for both microgrids for load frequency control and spinning reserve purpose. As a result, DEGs can be economically operated with great flexibility. However, the ON/OFF cycle of DEG increases. Further research is required to drive the operating strategies of DEG to reduce ON/OFF cycle. 


\section{REFERENCES}

[1] S. Chowdhury, et al., "Microgrids and Active Distribution Networks," The Institution of Engineering and Technology, Renewable Energy Series, vol. 6, 2009.

[2] N. J. Gil, and J. A. P. Lopes, "Hierarchical Frequency Control Scheme for Islanded Multi-Microgrids Operation," IEEE Lausanne Power Tech Lausanne, pp. 473-478, 2007.

[3] M. U. Usama, et al., "Utilizing Spinning Reserves as Energy Storage for Renewable Energy Integration," Power Systems Conference, Clemson University, pp. 1-5, 2014.

[4] S. K. Aditya, and D. Das, "Load-Frequency Control of an Interconnected Hydro-Thermal Power System with New Area Control Error Considering Battery Energy Storage Facility," International Journal of Energy Research, vol. 24, pp. 525-538, 2000.

[5] F. Katiraei, et al., "Microgrids Management: Controls and Operation Aspects of Microgrids," IEEE Power and Energy Magazine, 2008.

[6] F. Shahnia, "System of Interconnected Microgrid-Challenges and Solution," 2017. Available online at: pace.ee.uwa.edu.au/wp-content/uploads/2017/03/flyer-s006.pdf.

[7] K. X. Guoa, et al., "New Power Management Strategies for a Microgrid with Energy Storage Systems," Energy Procardia, vol. 16, pp. 1678-1684, 2012.

[8] J. Y. Kim, et al., "Performance Evaluation of Microgrid Management Function in KERI pilot plant," Int. Conf. on Renewable Energies and Power Quality (ICREPQ'10), Granada (Spain), pp. 196-201, 2010.

[9] A. Berrada and K. Loudiyi, "Optimal Modeling of Energy Storage System" International Journal of Modeling and Optimization, vol/issue: 5(1), 2015.

[10] "Energy storage is a key ingredient for all microgrids," 2015. http://www.renewableenergyworld.com/ articles/2015/10/energy-storage-is-a-key-ingredient-for-all-microgrids.html.

[11] H. Alharbi and K. Bhattacharya, "Optimal Sizing of Battery Energy Storage Systems for Microgrids," 2014 IEEE Electrical Power and Energy Conference, Calgary, Canada, 2014.

[12] S. X. Chen and H. B. Gooi, "Sizing of Energy Storage System for Microgrids," IEEE Transactions on Smart Grid, vol/issue: 3(1), pp. 142-151.

[13] Y. Wang, et al., "Coordinated Control of Battery Energy Storage System in a Microgrid," Conference 2013 IEEE PES Asia-Pacific Power and Energy Engineering Conference, 2013.

[14] Abbey C. and Joós G., "A stochastic optimization approach to rating of energy storage systems in wind-diesel isolated grids," IEEE Trans. Power Syst., vol. 24, pp. 418-426, 2009.

[15] D. J. Lee, and L. Wang, "Small-Signal Stability Analysis of an Autonomous Hybrid Renewable Energy Power Generation/Energy Storage System Part I: Time-Domain Simulations," IEEE Transactions on Energy Conversion, vol/issue: 23(1), pp. 311-320, 2008.

[16] S. H. El-Hefnawi, "Photovoltaic Diesel-Generator Hybrid Power System Sizing," Renewable Energy, vol/issue: 13(1), pp. 33-40, 1998.

[17] F. Katiraei and C. Abbey, "Diesel Plant Sizing and Performance Analysis of a Remote Wind-Diesel Microgrid," Power Engineering Society General Meeting, 2007.

[18] C. Wang, et al., "Cooperative Operation and Optimal Design for Islanded Microgrid," Innovative Smart Grid Technologies (ISGT), pp. 1-8, 2012.

[19] P. K. Ray, et al., "Small-Signal Analysis of Autonomous Hybrid Distributed Generation Systems in Presence of Ultracapacitor and Tie-Line Operation," Journal of Electrical Engineering, vol/issue: 61(4), pp. 205-214, 2010.

[20] S. Chanana and A. Kumar, "Operation and control of BESS using frequency-linked pricing in real-time market with high wind penetration," International Journal of Energy Sector Management, vol/issue: 5(4), pp. 585-602, 2011.

[21] D. Kottick, et al., "Battery Energy Storage for frequency regulation in an Island Power System," IEEE Transactions on Energy Conversion, vol/issue: 8(3), pp. 455-459, 1993.

[22] H. Bevrani, et al., "Intelligent Frequency Control in an AC Microgrid: Online PSO-Based Fuzzy Tuning Approach," IEEE Transactions on Smart Grid, vol/issue: 3(4), pp. 1935-1944, 2012.

[23] T. Senjyu, et al., "A Hybrid Power System Using Alternative Energy Facilities in Isolated Island," IEEE Transactions on Energy Conversion, vol/issue: 20(2), pp. 406-414, 2005.

[24] M. Dris and B. Djilani, "Hybrid System Power Generation 'Wind-photovoltaic' Connected to the Electrical Network 220 kV," International Journal of Applied Power Engineering, vol/issue: 7(1), pp. 10-17, 2018.

[25] M. A. M. Albreem and R. M. Aspan, "Micro Hydropower System Design for Gua Kelam Electricity Supply," International Journal of Applied Power Engineering, vol/issue: 7(2), pp. 116-118, 2018.

[26] N. Karthik, et al., "Optimal Operation of Microgrids-A Survey," International Journal of Applied Power Engineering, vol/issue: 7(2), pp. 179-186, 2018. 